contribution to radiation dosage. Besides the public, we must consider the worker using radiation or radioactive materials who is exposed to a higher degree of hazard. What dose, if any, can we tolerate, or what dose produces significant effects, either somatic or genetic ? These are all questions which are raised and discussed by Prof. Mayneord.

Roughly two-thirds of the book are devoted to information-the nature, origin and effects of radiation. Here we have much to interest the scientist and the informed layman. Even the expert in the field should not despise this section, since it holds a vast range of data, presented concisely and in readable form. The expert, however, may find more of interest in the second part entitled "Some Social Problems in the Control of Radiation". Here Prof. Mayneord compares the relative hazards from ionizing radiation with those from other occupations and pastimes. When we consider that in Britain alone in $1963,7,000$ people were killed in road accidents, why do we concern ourselves over a hazard which we believe may result in ten or twenty deaths per thousand million man-hours? The sports of mountaineering and boxing carry very much higher death rates, yet we accept these with comparatively little concern.

In the United Kingdom, during the period 1957-8, it was estimated that the use of radioactive materials in industry saved some $£ 3.5$ million. Can we therefore balance the benefit against the risks? Prof. Mayneord does not think this can be done on a numerical basis; the data serve only to illustrate the absurdities of the relative emphasis placed on radiation hazards. There is room for a new appraisal of the limits of our ignorance, as a result of which we may be able to modify our standards of protection.

This book was written more for the informed layman than for the scientist, but even experts in the field will find much to interest them and set them thinking. If the book has a fault it is in the price, which grossly undervalues it and can scarcely pay for the binding.

HUgh D. Evans

\section{TRANSMITTERS AND FALSE TRANSMITTERS}

\section{Biogenic Amines}

Edited by Harold E. Himwich and Williamina A. Himwich. (Progress in Brain Research, Vol. 8.) Pp. xiii +250. (Amstordam, London and New York: Elsevier Publishing Company, 1964.) $80 s$.

T the darkness which still surrounds the baffling problem of mental disease, each tiny ray of scientific light is eagerly welcomed. The physiological and biochemical exploration of nervous conduction and transmission seems at present to afford one of the more hopeful approaches to the comprehension of behaviour. It is therefore no accident that the symposium on "Biogenic Amines", recorded in Volume 8 of Progress in Brain Research, took place in a mental hospital.

The concept of chemical transmission across the synaptic or neuromuscular cleft has gained much in clarity with the demonstration of specific storage vesicles in the presynaptic nerve terminals from which the transmitter is presumably released by a suitable impulse. The articles of Whittaker and De Robertis, amply illustrated with beautiful photographs, vividly summarize the electronmicroscopic evidence and the correlated biochemical findings. No less remarkable are the light-microscopic investigations of Falck, whose fluorescence technique makes it possible to visualize nerve cells and axons containing catecholamines or serotonin and, moreover, to differentiate betweon these two groups of amines.

The area where the new concepts have been particularly fruitful is that concerning the mechanism of action of drugs affecting the central or peripheral autonomic nervous system. Some of these drugs have important behavioural or psychological effects and are therefore utilized as antidepressants, tranquillizers, hallucinogens, etc. It is now possible, in many cases, to interpret their actions in terms of interference with the normal function of the storage particles as it affects the uptake, retention or release of the neurotransmitter. In other cases, the interference pertains to reactions of biosynthesis or breakdown of the transmitter molecule or to the interaction between transmitter and receptor. Of particular interest. are those drugs which are believed to displace, directly or indirectly, the normal transmitter in the storage particle by a closely similar, but biologically less active, counterfeit molecule. These matters are dealt with in articles by Carlsson, Axelrod, Costa and Brodie, and others. To be sure, not everything is as tidy as one might wish. It is apparent, for example, from the contribution of Giarman and his associates that the action of reserpine is still imperfectly understood, and that the hypothesis according to which this drug merely results in the transfer of the transmitter from the particle-bound to the cytoplasmic fraction is a gross over-simplification.

It is notable that most contributors to this symposium presented very recent original research of their own. The result is a mosaic which is somewhat uneven, inasmuch as we find side by side facts which are fundamental, puzzling or irrelevant, minute detail and sweeping perspectives, considerable overlap and glaring gaps. The question which has been asked before in this context arises again: cui bono? Undoubtedly, the participants in a symposium of this kind may reap rich benefit in the form of advance information, stimulation by personal contacts and clarification of controversial issues. No criticism of symposia in general or this symposium in particular is intended. But by the time the record is published in book form the expert will be familiar with much of the work from regular channels of publication; some of it may strike him as already out of date. As for the outsider, he would be better advised to rely on one of the more balanced and critical reviews of the whole field, of which there is no dearth. This is not to deny that many of the contributions in Biogenic Amines are outstanding and well worth reading and that the book as a whole provides an interesting crosssection of research at a given point of time in a rapidly moving field.

H. WeIL-MaLherbe

\section{TUBERCULOSIS-A CONTINUING WORLD HEALTH PROBLEM}

\section{Chemotherapy of Tuberculosis}

Edited by Dr. V. C. Barry. Pp. viii +281 . (London: Butterworth and Co. (Publishers), Ltd., 1964.) 79s. 6d.

$\mathrm{D}^{\mathrm{F}}$ ESPITE all the advances of recent years in protection, and in detection and chemotherapeutic control of tuberculous infections, the disease still remains a major world health problem. Some of the reasons for this state of affairs are examined in Chemotherapy of Tuberculosis, which presents a wide-ranging survey of progress in the control of the disease and a timely reminder of the present need to re-direct attention to a long-standing problem, which to some extent has become overshadowed by preoccupation with other apparently more intransigent problems such as cancer. Many of its worst features are now virtually unknown in those technologically developed countries, where adequate food supplies and high standards of hygiene have banished hunger and poverty conditions in which tuberculosis flourishes. High standards of living have meant protection for children and young adults on an ever-widening scale by BCG immunization, while the use of mass radiography, with the help of modern drugs has brought about an enormous decline in mortality from 